\title{
Energy-efficient solar power plants for autonomous heat supply in Russia
}

\author{
Pavel Khavanov ${ }^{1, *}$ and Anatoly Chulenyov ${ }^{1}$ \\ ${ }^{1}$ Moscow State University of Civil Engineering, Yaroslavskoe shosse, 26, Moscow, 129337, Russia
}

\begin{abstract}
In the complex of measures for energy saving, partial replacement and reduction of consumption of fossil energy and electricity, water heating solar installations for heating systems have long been in practice for small energy facilities. Solar energy is one of the most dynamically developing directions of use of renewable energy sources, especially the introduction of which are associated with climatic conditions and technical requirements of their application. The territory of Russia is located mainly in the cold climatic zone and in regions with a sharply continental climate in which the operation of water heating solar plants is justified and most rational in seasonal use, in this case, their technical operation is carried out mainly during the non-heating period of the year. In such installations, in a number of cases, it is possible to avoid the need to use "non-freezing" heat carriers, and therefore the thermal schemes of the plants are simpler in design and cheaper, since heat exchangers or bivalent storage tanks can be excluded to transfer heat from the antifreeze to the water of the heating circuit or hot water system.
\end{abstract}

\section{Introduction}

In the warm period of the year, the resulting arrival of solar radiation from the surface of the solar receiver, given its thermal efficiency, is significantly higher than in the winter. Thus, the resources of helium flows in various regions of Russia (based on the results of generalized data from studies performed at the Institute of High Temperatures of the Russian Academy of Sciences) for the warm half-year (April-September) are 3.5-6.0 $\mathrm{kWh} / \mathrm{m}^{2}$ per day, with an average annual all year) $2.5-4.0 \mathrm{~kW} \cdot \mathrm{h} / \mathrm{m}^{2}$. The highest specific helium fluxes occur in the Krasnodar Territory, in the Northern Caucasus, Primorye, Southern Siberia, and at the same time in other regions of Russia, solar energy resources can also be considered sufficient [1]. This allows us to state that the possibilities of small solar energy in any case, with the seasonal receipt of heat for the purposes of autonomous heat supply, are available not only in the southern regions, but also in the middle zone of Russia.

A serious obstacle to the widespread introduction of solar installations is the low level of technical information of the population and the lack of state measures of material incentives, as well as the inability to provide a constant reliable and uninterrupted

\footnotetext{
* Corresponding author: roverton@mail.ru
} 
production of thermal energy for heat supply throughout the year without the use of (reserve) traditional energy sources [2].

Since the supply of solar energy is subject to seasonal and diurnal fluctuations, practically daily changes due to weather conditions, from zero to maximum during the day, the heat supply system in addition to the solar circuit (with a storage tank) should have a reserve source, for example, a fossil fuel boiler or an electric boiler with its automatic inclusion in the work of the system of autonomous heat supply in case of a lack of heat supply from the solar circuit [3]. The latter position should be provided in accordance with the requirement of the system design standards when using any unconventional energy source regardless of whether it works continuously or periodically (cyclically). For solar collectors, as low-potential heat sources, condensing boilers are most adapted for gaseous or liquid fuels [4], since they are adapted and have the greatest efficiency just by operating on a low-temperature coolant.

\section{Method}

The application of a specific scheme with the joint use of solar receivers (both panel and vacuum tubes) and condensing boilers is, of course, primarily determined by its functional purpose and the technical characteristics of the equipment used [5]. Consider the heat circuits starting with the simplest, designed only for hot water supply (fig. 1).

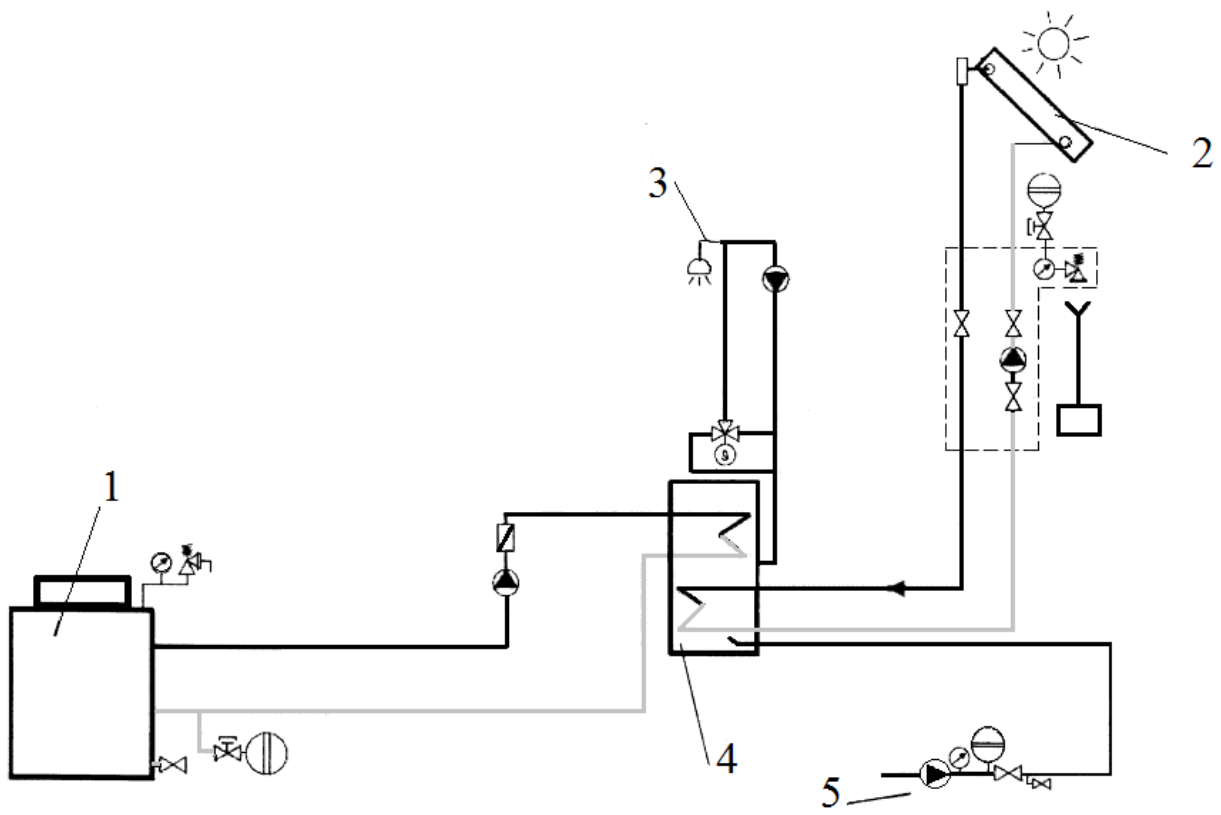

Fig. 1. Diagram of the use of a condensing boiler using panel solar collectors and solar collectors with vacuum tubes for the purposes of hot water supply: 1 - condensing boiler; 2 - solar collector with panel or vacuum tube solar collectors; 3 - hot water supply system and a layer-by-stage accumulator tank (bivalent); 5 - cold water supply system

In it, solar collectors are connected to the bottom heating element of a bi-valent accumulator tank, and to a top heater - a condensing boiler. Invariance of such a scheme is explained by the factors considered earlier and the limited time of operation of the solar installation with significant changes in the temperature of the coolant. 
Since the application of the boiler is regulated by regulatory documentation, it seems rational to combine into a single integrated scheme of hot water supply and heating systems [6]. Such a complex scheme with the use of an energy-saving condensing boiler and two storage tanks, combined with the above-mentioned scheme, when installed for the preparation of hot water tanks-accumulators of increased capacity, will provide partial coverage of the heat demand of the heating system during transitional periods of operation. The circuit of fig. 2. Thanks to the integrated approach, it can provide greater depth and accuracy of the use, distribution and regulation of the solar receivers and the system as a whole [7].

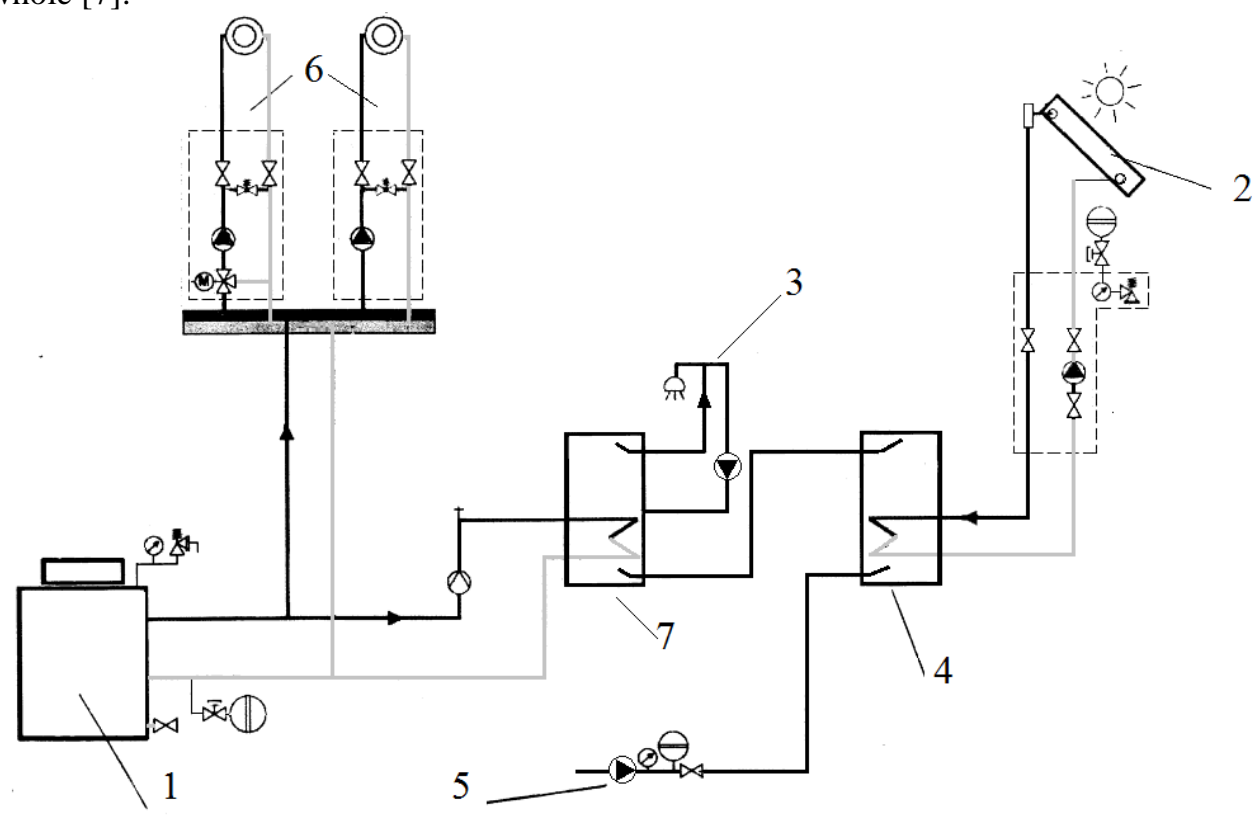

Fig. 2. Diagram of the use of a condensing boiler using battery-accumulators of the boiler circuit and solar receivers: 1 - condensing boiler; 2 - solar collector; 3 - hot water supply system; 4 - accumulator tank of solar receivers; 5 - cold water supply system; 6 - local heating systems; condensing boiler storage tank

Close to the algorithm of management and organization of work, a complex system of autonomous heat supply can be created using a bivalent multi-circuit tank [8] - a battery for hot water supply (fig. 3). 


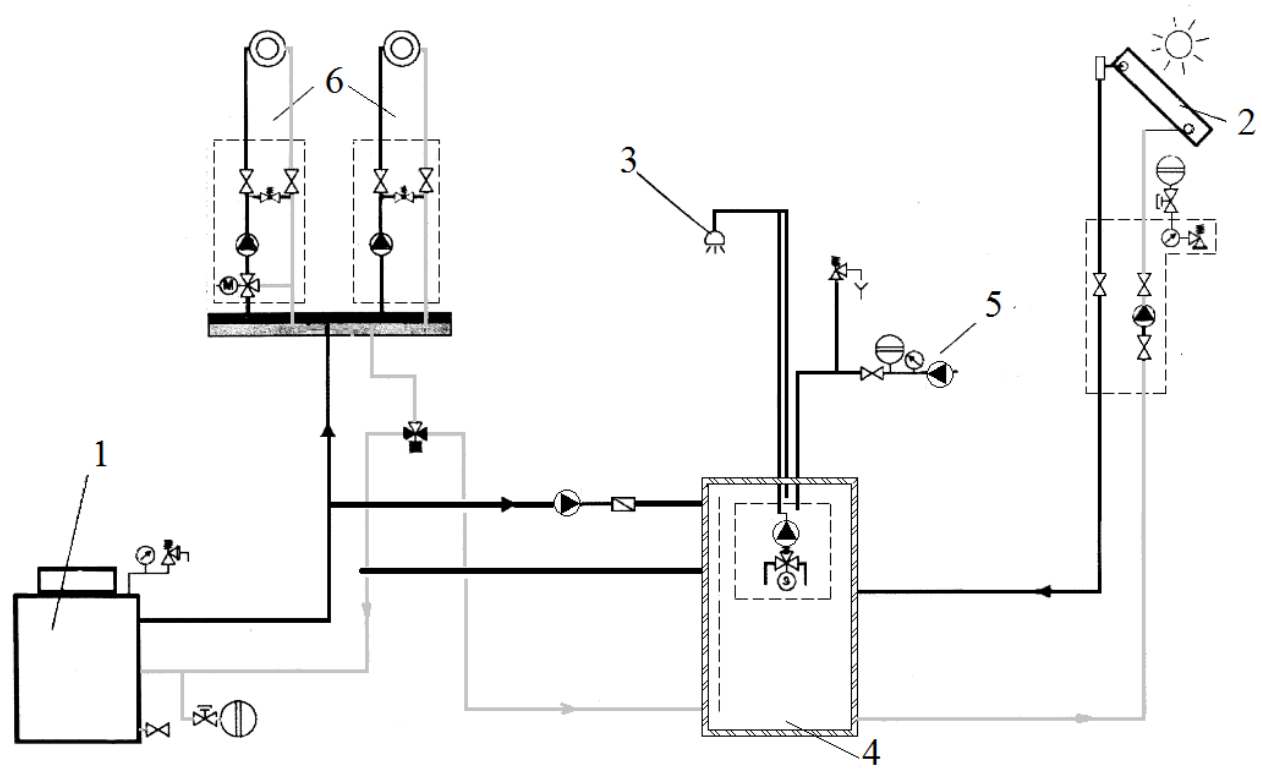

Fig. 3. Diagram of the application of the condensing boiler together with the solar collector and the bivalent storage tank-layer heater: 1 - condensing boiler; 2 - solar collector; 3 - hot water supply system; 4 - tank-battery layer heating (bivalent); 5 - cold water supply system; 6 - local heating system

Such a tank - the battery is divided vertically into zones stratified by temperature, and makes it possible to rationally use and distribute the load in accordance with the conditions of generation and consumption of heat [9]. This scheme requires a fairly complex automated control system, however, it also allows the creation of energy-saving complex systems combining several alternative sources of heat generation on its basis. For example, an autonomous heat supply system (fig. 4). using solar collectors and a ground-water heat pump system [10]. 


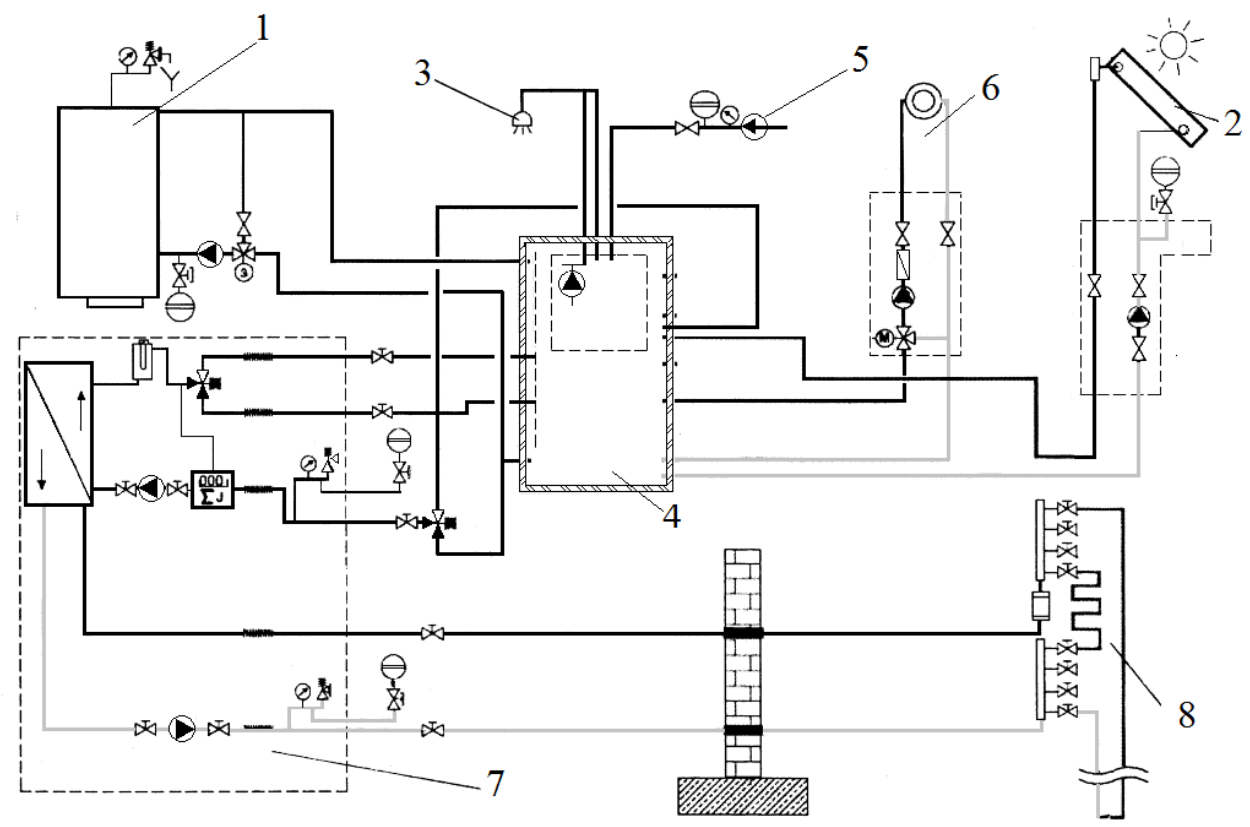

Fig. 4. Diagram of a combined system of autonomous heat supply with condensing boilers, solar collectors and a ground-water heat pump: 1 - condensing boiler; 2 - solar collector; 3 - hot water supply system; 4 - tank-battery layer heating (bivalent); 5 - cold water supply system; 6 - local heating system; 7 - heat pump; 8 - heat-recovery pipes of the ground-water heat pump

\section{Results}

It is obvious that solar systems, no matter what schematic solutions are presented, replace only a part of the heat demand of the DHW system (or the heat supply system) and for the climatic zones of Russia, according to the most optimistic estimates, can ensure a maximum saving of up to $45 \%$ of the energy expended during the year the purpose of DHW and up to $15 \%$ of the energy expended for heating purposes, which provides an appropriate fuel economy [11]. The use of electricity (electrode boilers, etc.) in autonomous heat supply systems due to a small proportion of heat input during the year (up to $25 \%$ ) can not be considered an energy efficient and energy-saving solution.

The most important factors determining the efficiency of the solar system (with the identity of geographic and climatic conditions) are the technical perfection of solar collectors (their effective optical efficiency and the integral coefficient of heat losses of the surfaces to the external environment $\mathrm{W} / \mathrm{m}^{2} \cdot{ }^{\circ} \mathrm{C}$ ), and the correct installation and installation of collectors. Calculations and operational experience confirmed that irrespective of the type of solar collectors (flat panel or vacuum tubes), rational angles of installation of collectors are determined by the period of their operation and for the southern orientation used in practice make up [12]:

- for year-round installations, the angle of inclination should be taken equal to the latitude of the terrain $(\varphi)$;

- for the exploited only in the non-heating (summer) period $\varphi=-15^{\circ}$;

- for those working in the heating season $\varphi=+15^{\circ}$.

In all cases, with an arbitrary arrangement of the collectors for angles of inclination $\varphi=$ $\pm 15^{\circ}$, deviation from the southern orientation by $10^{\circ}$ changes the total annual flux of solar radiation by no more than $5 \%$, with a deviation of up to $20^{\circ}$ - by $10 \%$; up to $30^{\circ}$ - by $15 \%$. 
Modern solar collectors of various types are the result of many years of activity of designers aimed at creating rational highly effective, reliable and practical designs, using scientific and technical achievements in this field [13].

If we analyze the design of solar receivers for autonomous heat supply, then the line is represented by collectors of two main types:

- flat (passive) solar collectors without concentrators with high optical efficiency and effective thermal insulation;

- tubular passive (with the presence of conditional concentrators) vacuum solar collectors, which have high selectivity with minimum values of heat losses [14].

\section{Conclusion}

Most domestic and foreign manufacturers produce both complete sets of equipment, automated control systems and installation accessories for the schemes considered, and the entire elemental base for the development of heliosystems for hot water supply and heating for individual projects.

The considered schemes and complex decisions, certainly should be considered as private decisions, however they seem the most rational from the viewpoint of energy and resource saving. From a large number of solar systems that differ [15]: - by designation (DHW systems, heating and heating systems); - duration and mode of operation; - by type of coolant used (water, antifreeze, air); - according to the technical solution (single-circuit, multi-circuit), - those are chosen which do not contain extremely expensive elements and, depending on the climatic conditions of operation, can most fully meet energy efficiency requirements when using high-tech and modern equipment.

\section{References}

1. J. Caudal, B. Fiorina, O. Labegorre, O. Gicquel. Fuel the Processing Technology $134 \mathrm{pp}$ 231-242 (2015)

2. D. O. Ferreira, M. Cardoso. Fuel the Processing Technology 91 issue 7 pp 789-798 (2010)

3. F. Jia Liu, H. Wen Combustion's and the Flame 138 issue 3 pp 295-303 (2008)

4. F. E. Kudryavtsev Proceedings of the All-Russian Student Scientific Conference The Ministry of Agriculture of the Russian Federation p. 148 (2014)

5. I. Ermakov, M. Lopatkin, D. Troshin, A. Kukushkin, P. Ermakov Technical supervision 1(110) p. 100 (2016)

6. P.A. Khavanov Sources of heat autonomous heating systems: monography. Moscow. MGSU. (2014)

7. P.A. Khavanov, A.S. Chulenyov. Development of rational systems of autonomous heat supply with the use of condensation technology. Dissertation for the degree of candidate of technical sciences. Moscow. National Research University Moscow State University of Civil Engineering (2016)

8. S. Kalchevsky Renewable energy sources, waste energy in industry. Sofia. Avangard Prima. (2012)

9. L.M. Akimov, P. Vinogradov, E.1. Akimov. Analysis of the influence of the functionalplanning structure of the city on air pollution contamination. Environmental assessment and mapping urban atmospheric condition. Voronezh State University. Voronezh, pp. 55-65. (2014)

10. K.J. Bell, M.A. Ghaly An Approximate Generalized Design Method for Multicomponent/Partial Condensers, AICh E Symp. 131: pp. 72 - 79 (1972) 
11. ONE-86. The method of calculating the ambient concentrations of harmful substances in the emissions of the enterprises. Leningrad. Gidrometeoizdat (1987).

12. P.A. Khavanov, A.S. Chulenyov Water-glycol coolants in offline heat supply. Scientific review \# 22, pp. 13-16 (2016)

13. A. I. Sharipov. Economy, ecology and energy efficiency for affordable housing. Energy saving \# 1, pp. 12-15 (2008)

14. A.L. London, V.M. Case. Compact Heat Exchangers. Moscow. Energiya. (1962)

15. O.N. Bruykhanov, S.N. Shevchenko. Heat and Mass Transfer. Textbook. Moscow. Infra-M. (2014) 